\title{
PARA A CONSTRUÇÃO DA NAÇÃO: DEBATES BRASILEIROS SOBRE EDUCAÇÃO DO CORPO NA DÉCADA DE 1930
}

\author{
EDIVALDo Góis JUNIOR* \\ Victor Andrade de Melo* \\ Antônio Jorge Gonçalves SoAres ${ }^{* * *}$
}

\begin{abstract}
RESUMO: Qual seria a melhor estratégia de educaçáo corporal? Esse foi um debate que progressivamente foi se apresentando como importante em um país que necessitava forjar seus discursos identitários. Analisar esse debate pode ajudar a melhor compreender os projetos de modernidade em conflito no Brasil das primeiras décadas do século XX. Tendo em vista tal consideração, esse estudo tem por objetivo discutir as defesas e contestaçóes à ginástica e aos esportes apresentados em artigos publicados nos periódicos: Educação Physica e Revista de Educação Física do Exército. Adotou-se como recorte temporal a década de 1930, momento crucial tanto no que se refere à construção de representaçôes identitárias sobre o país quanto no que tange à estruturação da educação física e do esporte nacional.
\end{abstract}

Palavras-chave: História; Educação; Educação Física.

\section{FOR THE CONSTRUCTION OF A NATION: BRAZILIAN DEBATES ON THE EDUCATION OF THE BODY IN THE 1930'S}

\begin{abstract}
Which would be the best strategy for body education? This was a debate that was increasingly becoming important in a country that needed to forge its identitary discourses in the early decades of the 20thcentury. Analyzing this debate can help us better understand the projects of modernity in conflict in Brazil in that period. Based on this scenario, this study aims to discuss considerations about sports and gymnastics in articles published in the journals Educação Physica and Revista de Educação Física do Exército. As a temporal cut we have selected
\end{abstract}

\footnotetext{
* Universidade Estadual de Campinas, Faculdade de Educação Física, Campinas, SP., Brasil. E-mail de contato: egoisjunior@gmail.com.

** Universidade Federal do Rio de Janeiro, Programa de Pós-graduaçáo em História Comparada, Rio de Janeiro, RJ., Brasil. E-mail de contato: victor.a.melo@uol.com.br.

*** Universidade Federal do Rio de Janeiro, Programa de Pós-graduação em Educação, Rio de Janeiro, RJ., Brasil. E-mail de contato: ajgsoares@gmail.com.
} 
the decade of 1930, a crucial moment in the process of the construction of the country's identitary representations with regards to the structuring of physical education and the national sporting system.

Keywords: History; Education; Physical Education.

\section{POUR LA CONSTRUCTION DE LA NATION: LES DÉBATS BRÉSILIENS SUR L'ÉDUCATION DU CORPS AU LONG DES ANNÉES 1930}

RÉSUMÉ: Quelle serait la meilleure stratégie pour l'éducation du corps? C'est un débat qui peu à peu apparait comme important dans un pays qui avait besoin de forger son discours pour former une identité. Cette analyse peut nous aider à mieux comprendre les projets de la modernité en conflit au Brésil dans les premières décennies du XXe siècle. Compte tenu de cette considération, cette étude vise à examiner les moyens de défense et objections sur gymnastique et sports, présentés dans des articles publiés dans des revues: Educação Physica et Revista de Educação Física do Exército. On a adopté la période des années 1930, un moment crucial en ce qui concerne la construction des représentations du pays, et également en ce qui concerne la structuration de l'éducation physique et du sport national.

Mots-clés: Histoire; Education; L'éducation physique.

\section{Introdução}

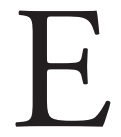

ntre os anos de 1921 e 1922, Artur Neiva ${ }^{1}$, membro da Sociedade Eugênica de São Paulo, publicou, em O Estado de S. Paulo, seis artigos nos quais enfaticamente sugeria que o esporte poderia ser uma verdadeira instituição redentora de nosso país. Para o médico, a prática teria grande potencial para contribuir com a manutenção da saúde e com o aperfeiçoamento da raça brasileira, não devendo, todavia, ser praticado de forma desordenada. O médico, de acordo com Gomes e Dalben (2011), estava dialogando com a, na ocasião recém-publicada, obra de Carlos Sussekind de Mendonça (1921): O sport está deseducando a mocidade brasileira. ${ }^{2}$

Sussekind de Mendonça, ao contrário de Neiva, inferia que a prática de esportes trazia mais malefícios do que benefícios, na medida em que ocasionava, em tese, uma excessiva fadiga corporal que desequilibrava o organismo, sendo, portanto, anti-higiênico. Mais ainda, a prática, sobretudo o futebol, afastava a juventude dos livros e de uma vida intelectual saudável. ${ }^{3}$ 
Destaque-se que a polêmica entre Mendonça e Neiva se deu no momento em que o esporte já se encontrava altamente disseminado no cotidiano das grandes cidades brasileiras, especialmente o futebol, que arrastava verdadeiras multidóes para os estádios, um dos motivos que explica o crescimento das preocupaçóes relacionadas a seus valores formativos, algo que era notável desde os anos iniciais do século XX, quando a prática começara a se expandir (PEREIRA, 2000; MELO, 2001). Por exemplo, no periódico O Malho, podemos encontrar charges que ironizam as deformaçóes físicas causadas pelas diferentes modalidades esportivas. $\mathrm{O}$ modelo britânico do sportsman, com seus músculos em destaque, se chocava com o tipo intelectual romântico Musset. ${ }^{4}$

Ao redor dessa polêmica havia um antigo debate: qual seria a estratégia mais adequada para a educação do corpo? Como pano de fundo da discussão, havia uma série de argumentos e contra-argumentos científicos sobre os exercícios, relativos a seus impactos tanto "físicos" (por exemplo, a preocupação com a fadiga) quanto "morais" (isso é, nos comportamentos dos praticantes), esgrimidos pelos saberes médicos que circulavam no Brasil desde a metade do século XIX, notadamente na produção originada nas Faculdades de Medicina. ${ }^{5}$ (PAIVA, 2003; GONDRA, 2004)

Reproduzia-se, no Brasil, o fervilhante debate que houve, na França do fim século XIX, entre os defensores da ginástica, organizados em torno dos métodos sueco, francês ou natural de Hébert, e os entusiastas do esporte, que, liderados por Pierre de Coubertin, dialogavam com a experiência inglesa. (WEBER, 1988)

No Brasil, nas primeiras décadas do século XX, os argumentos contrários ao esporte não eram somente de natureza "científica", mas também de ordem cultural. Por exemplo, Lima Barreto, em 1918, no artigo intitulado Sobre o foot- ball, entre várias outras crônicas, atacou a modalidade em função do seu caráter elitista e segregador. Para ele, até mesmo a, na ocasião usual, adoção de termos ingleses soava como ridículo. (AUGUSTO, 2006; CAPRARO, 2007)

Graciliano Ramos, em Traços a esmo, crônica publicada em $O$ Índio (1921), profetizava que o futebol seria "fogo de palha", pois, tendo esportes nacionais em quantidade, não adotaríamos práticas "estrangeiras". Sua ácida e irônica crítica coloca em questão a assimilação fútil da moda e dos estrangeirismos em detrimento da valorização da cultura brasileira. $\mathrm{O}$ autor contrapóe o sertanejo ao homem da cidade grande, indicando a debilidade da raça como um importante tema, para o qual não teriam grandes contribuiçóes as práticas esportivas, dado sua incapacidade regeneradora. (SOARES; LOVISOLO, 1997)

Esporte ou ginástica: qual seria a melhor estratégia de educação corporal? Esse foi um debate que, desde o século XIX, progressivamente tornou-se importante para um país que necessitava forjar discursos identitários, elementos fundamentais para consolidar a ideia de nação. Analisar esse debate pode ser útil 
não só para discutir a disciplina Educação Física, como também para ajudar a melhor compreender os projetos de modernidade em conflito no Brasil nas primeiras décadas do século XX.

Tendo em vista tal consideração, esse estudo tem por objetivo discutir os elogios e contestaçóes ao esporte e à ginástica apresentados em artigos publicados nos periódicos Educação Physica e Revista de Educação Física do Exército. Adotou-se como recorte temporal a década de 1930, momento crucial tanto no que se refere à construção de representaçóes identitárias sobre o país quanto no que tange à estruturação da educação física e do esporte nacional. (DRUMMOND, 2008)

Educação Physica foi o primeiro periódico comercial brasileiro dedicado ao tema, publicado, entre os anos de 1932 e 1945, pela Companhia Brasil Editora. Foi dirigido inicialmente por Paulo Lotufo e Oswaldo Murgel Resende. A partir de 1936, Roland de Souza foi seu editor; entre 1939 e 1944, foi liderado por Hollanda Loyola. Contava com a colaboração de outros importantes nomes da educação física nacional: Américo Netto, professor da Escola de Educação Física do Governo do Estado de São Paulo; Henry Sims, diretor da Associação Cristã de Moços do Rio de Janeiro; Fred Brow, técnico da Confederação Brasileira de Desportos; Georges Summers, da Associação Cristã de Moços da América do Sul, entre outros. ${ }^{6}$

A revista foi um dos principais veículos de divulgação da Educação Física no Brasil. (SCHNEIDER, 2010) Seus objetivos e ideais eram assim apresentados:

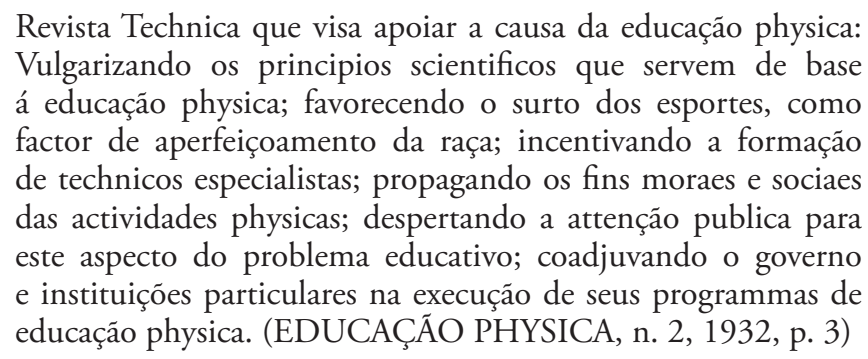

Já a Revista de Educação Física do Exército, periódico oficial dessa força armada, tem sido publicada desde maio de 1932, sob a responsabilidade da Escola de Educaçẫo Física do Exército. Foi criada pelo Coronel Newton Cavalcanti e dirigida, na década de 1930, pelo Major Raul Mendes de Vasconcelos, tendo como redator o Capitão Inácio de Freitas Rolim. A partir de 1939, a direção da revista passou a ser exercida pelo Tenente-Coronel Otavio Saldanha Mazza. ${ }^{7}$

Como veículo oficial, o periódico circulava mensagens de interesse governamental, notadamente propagando os objetivos das forças armadas no campo da Educação Física, da Educação e da formação de uma identidade nacional. Seus 
colaboradores eram militares de diferentes patentes, com prevalência de oficiais; ainda assim, contou com a participação de autores civis. (FERREIRA NETO; MAIA; BERMOND, 2003)

Como o debate sobre o qual vamos nos debruçar de alguma forma reverbera uma discussão que se inicia no Brasil das décadas finais do século XIX, começaremos por discutir a configuração da ideia de educação do corpo nos anos oitocentistas.

\section{Configurações da educação corporal no século XIX}

As preocupaçóes de natureza higiênica e militar, as demandas do processo de modernização do país e o diagnóstico da debilidade da raça foram elementos presentes na construção de discursos sobre a educação do corpo no Brasil do século XIX.

Náo surpreende, assim, que a Guerra do Paraguai, que ocupou um espaço importante no imaginário do país naquela época, tenha desencadeado o aumento das preocupaçóes com a formação do cidadão e sua preparação para servir à pátria. Ainda que o Brasil tenha se sagrado vencedor no conflito bélico, os vultosos gastos e as dificuldades enfrentadas pelas forças brasileiras expuseram as fragilidades do povo e da defesa nacional. (CARVALHO, 2012)

Tornava-se explícita a necessidade de considerar mais seriamente estratégias destinadas a forjar o corpo e o espírito do brasileiro, algo que se tornou notável no escrito de um dos médicos envolvidos com o conflito, Eduardo Augusto Pereira de Abreu, autor de Estudos higiênicos sobre a educação física, intelectual e moral do soldado: escolha do pessoal para a boa organização do nosso Exército, lançado em 1867 antes do fim da Guerra. (SILVA; MELO, 2011)

$\mathrm{Na}$ verdade, a despeito desse verdadeiro "alerta", não foi a primeira vez que o tema se fez presente nas preocupaçóes de intelectuais brasileiros. Por exemplo, foram dedicadas ao assunto algumas das teses exigidas para a concessão do título de doutor, que passaram a ser obrigatórias a partir da reformulação da Faculdade de Medicina do Rio de Janeiro, no segundo quartel do século XIX. Esse indício pode ser lido como consequência do aumento das preocupaçóes com a saúde da população e com o saneamento da capital, expressão dos movimentos de modernização da sociedade brasileira. Nesses trabalhos, a Educação Física ainda não era considerada como uma disciplina escolar, mas sim como um conjunto de cuidados ligados à higiene, à puericultura e também, de forma geral, à prática de atividades físicas. (PAIVA, 2003; GONDRA, 2004)

No que se refere às propostas governamentais, no decorrer das primeiras décadas do novo Império, o tema foi discutido já nas pioneiras iniciativas de 
estruturação da educação nacional. Por exemplo, na Constituinte de 1823, no âmbito do debate desencadeado pela Comissão de Instrução Pública, que propôs a realização de um concurso para a apresentação de um Tratado de educação física, moral e intelectual para a mocidade brasileira. Devemos destacar a posição de Luiz José de Carvalho e Melo, deputado pela Bahia, que defendeu explicitamente que:

[...] a educação física tinha importância fundamental no desenvolvimento da intelectualidade da mocidade. O corpo robusto, segundo ele, e a boa saúde dariam mais disponibilidade para os estudos. A educação física e a intelectualidade estavam ligadas. A educação na visão do deputado promove no homem a boa moral, os bons costumes e as virtudes cívicas. Isso o torna um cidadáo integrado à sociedade, honesto, probo e amigo da Pátria. (FERRONATO, 2006, p. 108)

De outro lado, Martim Francisco Ribeiro de Andrada, mesmo integrando a Comissão de Instrução Pública, ao apresentar um plano completo para a educação nacional, excluiu a educação física. De toda forma, o projeto não foi à frente; a constituinte, aliás, foi dissolvida. $\mathrm{O}$ tema tornou a ser contemplado na Reforma Couto Ferraz (BRASIL, 1854), na Reforma Leôncio de Carvalho (BRASIL, 1879) e recebeu grande atenção de Rui Barbosa no parecer sobre a reforma do ensino primário, em $1882 .{ }^{8}$

A bem da verdade, tratava-se de uma série de referências à ginástica, uma prática que, na segunda metade do século XIX, já se encontrava mais difundida. Um dos motivos dessa maior presença tinha relação com a maior presença de imigrantes no país: estrangeiros começaram a lecionar tanto em escolas quanto em salas particulares.

Além disso, em algumas cidades fundaram-se sociedades ginásticas que, ainda que de forma ocasional, contribuíram para a difusão da prática. Essas associaçôes foram muito atuantes na Regiâo Sul, onde era praticado o Turnen, que, como observa Tesche (2002), também incluía jogos, caminhadas, teatro e coral. Segundo esse autor, em 1859 fora criada, no Rio de Janeiro, a Sociedade Alemã de Ginástica, a primeira da América do Sul. Na capital também destacava-se a Sociedade Francesa de Ginástica, o Congresso Ginástico Português e o Clube Ginástico Português (fundado em 1868, até hoje ativo).

Outra motivação para a difusão da ginástica foi sua adoção como estratégia de formação no âmbito das Forças Armadas. A prática passou a ser considerada útil para a manutenção da boa forma do combatente e ferramenta eficaz de disciplinarização das tropas, algo que se tornara comum em outros países.

Oficialmente, o método alemáo foi o adotado pelo Exército, o que parece ter relação com a expressiva presença de soldados prussianos, contratados 
para a campanha contra Oribe e Rosas em 1851, e que por aqui ficaram servindo ao país, tendo participado também dos combates da Guerra do Paraguai. Não surpreende que, em 1870, o governo imperial tenha mandado distribuir o Novo guia para o ensino da ginástica nas escolas públicas da Prússia, traduzido por Joaquim Teixeira de Macedo, um dos intelectuais envolvidos com o desenvolvimento da educação pública nacional, defensor da adoção de princípios da pedagogia alemã. Esse é mais um indício de que a influência dos militares se estendeu ao meio civil, mesmo porque eles também lecionavam em escolas civis.

Paralelamente a esse processo de maior difusão da ginástica e conformação de uma disciplina escolar dedicada às atividades físicas, estruturava-se o campo esportivo no país, em período aproximadamente semelhante, não por acaso a partir dos anos finais da década de 1840, quando, com a assunçáo de D. Pedro II ao trono, observa-se uma maior estabilidade política no país, superando-se os intensos conflitos que marcaram tanto o período de D. Pedro I quanto o das regências. (CHALHOUB, 2012)

Depois de alguns fracassos, paulatinamente o turfe foi se estruturando e se estabelecendo como uma das práticas mais apreciadas tanto pelas elites quanto pelos populares. No final da década de 1880, chegaram a funcionar simultaneamente cinco agremiaçóes turfísticas, todas promovendo corridas que contavam com grande público. (MELO, 2009)

A valorização desses eventos é expressão de uma sociedade que buscava se sintonizar com as "novidades do mundo desenvolvido". A prática desempenhava, assim, certa função pedagógica, já que se estabelecia como uma arena de performances públicas, onde se desfilavam comportamentos socialmente valorizados, na mesma medida em que se explicitava quem é quem na ordem social, ocasião para os mais poderosos exibirem seus símbolos de status e distinção. Não surpreende que tais competiçóes, em vários sentidos, dramatizassem as tensôes do instante, tanto entre classes quanto intraclasse - os debates e conflitos de uma elite híbrida que transitava entre uma ordem aristocrática rural e um projeto urbano de industrialização.

A ideia de que se tratava de uma prática corporal de movimento não era tão notável no âmbito do turfe, a não ser pelo seu reverso: a configuração de certa desvalorização dos exercícios físicos por parte de certos grupos, que preferiam somente assistir cavalos a correr, conduzidos por homens (os jóqueis) normalmente oriundos das camadas populares. (MELO, 2009)

Um caráter de intervenção corporal mais explícito somente será observado com a conformação do remo, que foi antecedida por uma maior ocupação das praias, inicialmente por motivos terapêuticos e médicos.

Como causa e consequência das mudanças em marcha na sociedade brasileira, notadamente na capital, na década final do século XIX, o remo passou 
a ser encarado como uma prática saudável e higiênica, logo se tornando o esporte mais popular, estabelecendo inclusive uma tensão com o turfe - considerado por muitos como uma expressão de um passado monárquico e rural que deveria ser substituído pela cidade republicana. O esporte náutico influenciou a configuração de outras modalidades: a natação, o atletismo, o ciclismo. Os tipos físicos fortes e musculosos começaram a ser progressivamente valorizados, apesar de persistirem algumas resistências e estranhamentos. (MELO, 2011)

A essa altura algumas escolas instaladas no Brasil utilizavam o esporte como estratégia educacional. Além de alguns colégios religiosos, isso era observado em certas instituiçóes que procuravam se sintonizar com o que havia de mais avançado no cenário pedagógico mundial, como é o caso da Escola Normal de São Paulo (GÓIS JUNIOR; BATISTA, 2010) e do Colégio Pedro II. (CUNHA JÚNIOR, 2008)

A despeito desses exemplos elencados, havia muitas reticências à introdução do esporte nas escolas, mesmo que progressivamente a prática ganhasse visibilidade e legitimidade social. Esse debate prosseguiu nas primeiras décadas do século XX. Vejamos como ele se manifestou nos periódicos investigados.

\section{Críticas e defesas do esporte}

Nos periódicos investigados, diversos foram os argumentos apresentados para exaltar o valor do esporte. Resende (1932a, p. 15) ${ }^{9}$, por exemplo, influenciado pelo positivismo, infere:

A educaçáo positiva, como existencia que deverá preparar, su-
bordinará sempre o intelecto à sociedade, tomando esta como
fim e aquelle como meio, tal educação se constitúe a primeira
das artes, a única plenamente geral, que aperfeiçoa a acção,
melhorando o agente. Os sports collectivos, ao mesmo tempo
que robustecem o corpo e aprimoram os sentidos, desenvolve
o espírito associativo, compressor dos instinctos egoístas: habi-
tuam a submissão de certas regras, voluntariamente acceitas, e
cuja transgressão póde acarretar revezes para seu quadro.

O autor vislumbra um impacto dos esportes na educação moral da juventude, tendo em vista a construçấo de uma sociedade solidária. De fato, ideias como coletividade e espírito de grupo são sempre lembradas pelos defensores do esporte como ferramenta educacional. Por exemplo, o editorial Disciplina e Desporto destaca, ao exaltar o funcionamento da Polícia Especial: 
Isso se explica muito naturalmente pelo espírito que congrega todos os seus elementos, numa solidariedade, coêsão e entusiasmo inexcediveis. Essa coletividade conta entre os elementos que a compóem, um grande número de consumados atlétas e, depois, adóta os métodos mais científicos e modernos da Educação Física. Assim, pois, essa fôrça que reune e ordena os milicianos especializados da nossa cidade, é o produto quasi exclusivo da prática de desportos. São notoriais as virtudes da Educação Física sistematica, e, em especial dos jogos desportivos, a tal respeito. Eis pois, aí todo o segredo do brilho que ostenta a Policia Especial. Aquela disciplina, voluntariamente consentida de seus elementos, cousa náo muito comum em outros meios desportivos, é uma consequencia do cultivo metódico do Físico, buscando todo o proveito possivel da prática racional dos desportos individuais e coletivos. (RESENDE, 1933, p. 28)

Essas noçóes dialogavam tanto com as "necessidades contextuais" (as reflexóes sobre a construção de uma ideia de naçáo) quanto com a compreensão de que, por motivos diversos, a formação social brasileira era marcada por um extremado individualismo, "[...] pela despreocupação com o interesse coletivo, pela ausência de espírito público, de espírito do bem comum, de sentimento de solidariedade comunal e coletiva e pela carência de instituiçóes corporativas em prol do interesse do lugar, da vila, da cidade" (OLIVEIRA VIANNA, 1987, p. 110). O esporte, logo, poderia se um instrumento a serviço da educação de um povo diagnosticado como egoísta.

$\mathrm{Na}$ verdade, a rápida propagação do esporte e a criação das associações como um todo, no decorrer dos anos iniciais do século XX, já eram indícios dos limites da compreensão de Oliveira Vianna sobre o insolidarismo brasileiro. Para Fonseca (2008), essas entidades eram espaços de sociabilidade que atendiam a necessidades específicas, ligadas a um exercício possível da cidadania, que tinha em conta os limites do jogo político.

De toda forma, na apreensão do momento, os esportes, especialmente os coletivos, supostamente contribuiriam para forjar uma ética necessária ao processo de consolidação de uma unidade nacional, seria um forte aliado discursivo e pedagógico para fortalecer a "comunidade imaginada". (ANDERSON, 1991) A coesão era um valor constantemente mobilizado pelos defensores da prática:

[...] afirmando, com toda seriedade, que dois grandes factores concorrem para fortalecer a unidade espiritual do povo brasileiro: a música carnavalesca do Rio de Janeiro e o foot-ball. [...]. Podem os povos falar até línguas ou dialectos differentes; Para mim, em futuro distante, será a musica popular que fará que o rio-grandense do sul não se sinta de todo estrangeiro nas margens do Amazonas. [...]. Além da música, também os sports, 
principalmente, no momento, ao foot-ball, cabe papel saliente na obra de cohesão nacional. (RESENDE, 1932b, p. 51)

Destaque-se que não somente o futebol era visto como potencial para a construção do espírito de coesão nacional; as práticas individuais também eram mencionadas. Alamandei (1938, p. 6), por exemplo, infere:

Os campeóes de Atletismo, Natação e Box engrandecem o espírito nacional, não porque os vencedores sejam os atletas, os nadadores ou os pugilistas mais fortes do mundo, mas sim, porque sendo êles o expoente de uma seleção, revelam os esforços que centenas, milhares de jovens realizam, subordinando-se ao regímen, à disciplina, ao método, convencidos da bondade de uma causa e dispostos a seguí-la.

É nesta forma que os desportistas, espectadores e animadores, devem fortalecer e afiançar o sentimento de nacionalidade.

Articulado com a ideia de fortalecimento do espírito nacional, o esporte também esteve associado ao discurso eugenista, considerado como uma ferramenta que deveria estar a serviço do aperfeiçoamento da raça. Para Ramos (1936, p. 38):

Felizmente, todo o organismo, e, portanto, também o racial, procura algures o remédio de que carece. Cabe aos esportes suprir as falhas dos processos de seleção racial e do seu aperfeiçoamento.

O esporte, qualquer que seja a modalidade, robustece o individuo, tornando-o inaccessível aos males que possam debilitar. As naçóes sentem, nos seus sentimentos de existência coletiva, a necessidade incoercível de um organismo forte nos seus indivíduos.

Nas folhas dos periódicos, contudo, os elogios e a defesa do esporte não eram uma unanimidade. Publicaram-se algumas manifestações que, se não totalmente contrárias, ao menos apresentavam com sérias restrições à utilização da prática como meio de educação de crianças e jovens. Vejamos, por exemplo, o alerta de Hébert (1941, p. 58):

Pergunta-se por que motivo o esporte cada vez mais descamba para o espetáculo, o funambulismo, e para a exploração da basbacaria humana. Uma das principais razões é a seguinte. Lançou-se o esporte no país com processos de saltimbancos, e aplicou-se a publicidade do esporte industrial ao esporte corporal. Promoveram-se corridas, organizaram-se 'matches', de começo, com fim de propaganda completamente desinteressada, fôrça é 
reconhecê-lo. Mas, este movimento sadio não durou. De pressa se abriu a burra e a imprensa esportiva, como a grande imprensa, culpáveis nisso tanto uma como outra, fizeram exatamente o que fazem os mascates de estrada. Gabaram, muito alêm dos limites permitidos pelo bom senso, a excelência dos fenômenos que iam exibir ou opôr um a outro em impressionantes 'matches'. É suficiente reler os jornais destes vinte últimos anos, para ver que nada exageramos e que as louvaminhas usadas pela Imprensa para atrair a turba são mais ou menos as mesmas empregadas pelos mascates de estrada. $\mathrm{O}$ resultado de tais processos foi atrair o espectador e crear a indústria do espetáculo esportivo. Explorou-se a ingenuidade e a ignorância gerais, fazendo crer no valor extraordinário de alguns indivíduos, provenientes, em realidade, de uma seleçáo ínfima, o ataviando-os dos títulos pomposos de campeóes nacionais ou mundiais!

Há anos, os dirigentes das federaçôes ou sociedades de esporte trabalham, não a fisiologia ou a pedagogia dos exercícios do corpo, mas a maneira prática de criar uma reunião ou um espetáculo.

Perceba-se que o autor, um dos líderes dos movimentos ginásticos na França, não se refere especificamente ao cenário brasileiro. De toda forma, sua publicação no periódico pode ser encarada, no mínimo, como um alerta. Façamos uma digressão para lembrarmos que a crítica ao esporte realizada por Hébert (1925) se antecipa a críticas realizadas posteriormente durante todo o século XX que ganharão força no Brasil a partir dos anos de 1980. De fato, o que incomodava o mestre francês era o esporte espetáculo e competitivo que se contrapunha aos ideais utilitários da Educação Física. Ele não desvalorizava a prática em si, mas sim, os caminhos tomados pelos esportistas e pela indústria que se formou a partir desse fenômeno social:

No esporte exclusivo, o individualismo é exaltado pela idéia de
chegar em primeiro lugar ou de ser o mais forte. Tanto mais se
afirmam e se expressam os sentimentos egoístas, quanto maior
o exagero do esforço. Se o sucesso corôa os esforços, o amor
próprio super excitado tende a gerar a vaidade. (HÉBERT,
1941, p. 31)

Para Hébert, quando se considera o esporte apenas como um meio de se definir os melhores, o intuito de contribuir para com a saúde moral e física se perde e dá lugar à vaidade. Para que tivesse algum potencial educacional era preciso cercar-lhe de valores como cooperação e altruísmo. A referência negativa ao funambulismo, que serviria mais à exploração comercial do que à educação, é algo observável também na obra Da educação physica, o que ella é, o que tem sido, o que 
deveria ser, de Fernando de Azevedo (1920). Sua visão demarca a separação entre a utilidade e o simples exibicionismo por meio de performances corporais: "Nem se póde invocar contra Amorós o facto de haver elle estabelecido para esta sciencia quatro partes principais, sendo a ultima a gymnastica scenica ou a funambulica, quando tem para esta as pesadas palavras que acabamos de citar [...]” (p. 119).

A crítica de Azevedo ao funambulismo ajuda a entender suas restriçóes ao esporte. Em Educação Physica, Fernando Azevedo publicou dois artigos (1938, 1939) em que procurou apontar os limites da sua introdução na educação de crianças e jovens. Sua preocupação primeira é com a necessidade de organização de métodos de Educação Física adequados à idade dos alunos. Na sua visão, seria impreterível que os jogos infantis precedessem a ginástica científica, que por sua vez precederia a prática esportiva. ${ }^{10}$

O momento ideal para introduzir a prática esportiva, segundo o autor, seria a vida adulta, podendo até ser iniciada na adolescência, desde que por sugestão médica. Em contrapartida, a ginástica seria insubstituível em todas as faixas etárias:

É um erro palmar admittir-se que os jogos esportivos representam o mesmo papel que os movimentos gymnasticos no desenvolvimento physico do menino e do adolescente. Não exercendo senão certos músculos, e especialmente os dos membros, sendo irregulares, não podem favorecer, como os movimentos regulados, o desenvolvimento do tronco e a capacidade respiratória; além do que muitos d'elles, como os jogos da palma, o foot-ball, o cyclismo e outros, na opinião geral dos medicos, são mais próprios dos adolescentes e dos adultos do que dos meninos. A educação physica, pelos esportes, não póde substituir a gymnastica scientificamente administrada. (AZEVEDO, 1938, p. 10)

A exemplo de Hébert, Azevedo demonstrava preocupações com o uso desmedido da força, a especialização precoce e o caráter seletivo dos esportes. Percebe-se, de fato, a forte influência da cultura ginástica francesa e sueca no pensamento desse autor, em oposição a um modelo de educação física inglesa. Nos termos do autor:

Os inglezes intelligentes não vêm com prazer o exaggero dos exercícios physicos nas escolas inglezas. [...] vemos n'este a preferência decidida pela educação franceza, em quanto aquelle chega a attribuir em grande parte ao abuso dos exercícios physicos o perigoso desenvolvimento da grosseria e brutalidade que verifica na sociedade britannica. Não seria, pois, demais, se concluissemos com Payot, que não é á Inglaterra, rotineira e brutal, que devemos, sob este ponto de vista, imitar, mas sim á Suécia [...]. (AZEVEDO, 1938, p. 11) 
Argumentos semelhantes aos de Fernando de Azevedo são encontrados em diversos artigos publicados em Educação Physica, como os de Steinberg (1937), de Vintre (1939) e de Reggi (1941). São posicionamentos que revelam os limites e os cuidados necessários para a adoção do esporte como estratégia educacional, tais como a exigência de acompanhamento médico e o estabelecimento de uma idade ideal para começar a prática, a fim de evitar a especialização precoce, temas recorrentes ainda hoje no campo na Educação Física.

O esporte seria, assim, pouco indicado para crianças e adolescentes em função de gerar um prazer tão intenso e ser de tal forma absorvente que induziria a dispêndios excessivos de energia para corpos ainda náo robustos. O seu caráter agonístico levaria indivíduos não maduros biologicamente a colocar em risco sua saúde e seu desenvolvimento. De fato, se já não mais se demonizava o esporte, ainda persistiam muitas restrições.

\section{Considerações finais}

Na década de 1930, momento importante na consolidação da ideia de nação, no qual estavam imbricadas preocupaçôes com a educação física do povo brasileiro, ainda persistiam, nos periódicos especializados da área, no Brasil, polêmicas sobre a utilidade e os riscos de o esporte ser adotado em programas de educação corporal. Podemos até supor, a partir dos escritos de Americo Netto (1933), que a oposição pode ter sido até mesmo maior do que os documentos que investigamos revelam:

A ginástica e o desporto, ramos da educação física que deveriam sempre combinar-se, completando-se, têm ultimamente andado em vivo antagonismo, que aos dois prejudica.

Porque? Porque tanto um, como outro, querem ultrapassar os seus limites. O desporto quer começar muito cêdo e a ginástica pretende acabar muito tarde.

Daí, o conflito em que nenhum ganha e ambos perdem.

A escola dos que querem que a ginástica seja tudo, afirma que o homem deve praticá-la em todas as fáses da vida sempre com preponderancia quasi com exclusividade, sôbre qualquer outra atividade física. Diz ser essa disciplina indispensável, não só para a formação do homem físico, como tambem para sua manutenção no máximo da eficiencia. E, condena implacavelmente o desporto, chamando-o violento, excessivo e particularista.

Por sua vez, os partidários do desporto não concedem a menor trégua à ginástica. Julgam-na e sentenciam-na como enfadonha 
e fatigante, incapaz de despertar as mesmas grandes emoçôes da competição, da luta do indivíduo contra o indivíduo e do grupo contra o grupo. E enaltecem os concursos esportivos, como o único meio possível de criar e desenvolver energias, de dar aos caractéres essa tempera ao mesmo tempo flexível e fórte, que táo necessaria cada vez mais se torna na vida das sociedades modernas. E, como aplicação destas idéas, querem que o homem sómente pratique desportos, desde que nasce até morrer. Enganam-se ambos, tendo cada um deles sua parte de razáo. A ginástica e o desporto são atividades complementares uma da outra, inseparaveis em tudo que diz respeito á educação física. $\mathrm{O}$ que é preciso é dar a cada um o seu devido valor, no seu tempo próprio, colando-os em seus respectivos lugares. (NETTO, 1933, p. 29)

A rivalidade residia no debate sobre o melhor método para o ensino da Educação Física para crianças e jovens. Como desdobramento, de um lado, produziu-se uma idealização do valor do esporte. De outro, percebe-se uma forte suspeita de que estimularia excessos que comprometeriam a integridade dos educandos. Américo Netto assume no debate uma posição de conciliação, sugerindo que esportes e a ginástica devem ser complementares na formação de crianças e jovens.

No Brasil, esse debate adquiriu uma nova conformação no pós-2a Grande Guerra, com a adoção do método da Educação Física Desportiva Generalizada, que teve como um dos grandes divulgadores o francês Auguste Listello. A partir daí observou-se um processo contrário ao que vinha ocorrendo até então: a ginástica foi paulatinamente perdendo espaço e o esporte foi se conformando no principal, quando não no único, conteúdo trabalhado nas aulas de Educação Física.

Essa predominância vai ser questionada a partir dos anos 1980, no âmbito do movimento de renovação da Educação Física brasileira. Em um cenário em que se pretendia construir uma ideia de que a disciplina deveria contribuir para formar cidadãos críticos e participativos, o esporte passou a ser contestado por supostamente reproduzir valores de uma sociedade capitalista que precisava ser superada. (CAPARROZ, 2007)

Sugere-se a ampliação dos conteúdos escolares e o redimensionamento do esporte, sua utilização segundo novos parâmetros. Ainda assim, a velha ginástica não recuperou seu antigo prestígio, ficando mais restrita a ambientes não escolares (como academias e clubes). De qualquer forma, se os temas e focos da crítica mudaram, permanece a continuidade da disputa e da falta de consenso acerca do que é ensinar, para que ensinar e como ensinar as práticas corporais na escola. 


\section{Notas}

1. Neiva foi um dos mais importantes médicos das primeiras décadas do século XX. Ocupou importantes cargos, aliando atuação política e prática científica. Para mais informaçôes de sua atuação no âmbito educacional, ver Garchet (1993).

2. Esse trabalho recebeu auxílio financeiro do Conselho Nacional de Desenvolvimento Científico e Tecnológico (Demanda Universal/CNPq, Edital CNPq n. 14/2011); e da Fundação Carlos Chagas Filho de Amparo à Pesquisa do Estado do Rio de Janeiro (Edital FAPERJ "Apoio a projetos de pesquisa na área de Humanidades-2011").

3. Para mais informaçôes sobre o debate de Mendonça, ver Linhales (2006).

4. O francês Alfred de Musset foi um dos mais conhecidos e influentes expoentes do Romantismo no âmbito da literatura. Sua frágil compleição física e seus constantes problemas de saúde foram consagrados pela medicina com o termo "Sinal de Musset", para designar um indício de doença cardíaca.

5. Lembramos que, a partir de outro ponto de vista, o assunto já chamou a atençấo de Oliveira e Linhales (2011).

6. Para mais informaçôes sobre esses autores, ver Schneider e Ferreira Neto (2008).

7. Esses personagens desempenharam papel protagonista no desenvolvimento da educaçáo física nacional. Rolim, por exemplo, foi o primeiro diretor da Escola Nacional de Educação Física e Desportos, a primeira do país ligada a uma universidade (Universidade do Brasil). Cavalcanti foi diretor do importante Centro de Educação Física do Exército Brasileiro, instituição que antecedeu a criação da Escola de Educaçáo Física do Exército. Vasconcelos e Mazza, assim como Cavalcanti, foram comandantes dessa instituição.

8. Para mais informaçôes, ver Machado (2002).

9. Octávio Murgel Resende era irmão de um dos editores, Oswaldo Murgel Resende. No decorrer da segunda metade do século XX, destacou-se na carreira jurídica, chegando a ser ministro do $\mathrm{Su}$ perior Tribunal Militar.

10. Para um bom olhar sobre a relação de Azevedo com a Educaçáo Física, ver Pagni (1994) e Vechia e Lorenz (2009).

\section{Referências}

ABREU, E. A. P. Estudos hygienicos sobre a educação physica, intellectual e moral do soldado: escolha do pessoal para a boa organização do nosso Exército. Rio de Janeiro: [s.n.], 1867.

ALAMANDEI, P. G. O sentimento de nacionalidade no Esporte. Revista de Educação Física do Exército, Rio de Janeiro, n. 38, p. 6, ago. 1938.

ANDERSON, B. Comunidades imaginadas: reflexôes sobre a origem e a expansão do nacionalismo. Lisboa: Ediçóes 70, 1991.

AUGUSTO, E. C. Olho no lance: futebol e modernidade na crônica de Lima Barreto. In: ENCONTRO REGIONAL DE HISTÓRIA, 12., 2006, Rio de Janeiro. Anais... Rio de Janeiro: ANPUH/RJ, 2006. p. 1-9.

AZEVEDO, F. Os esportes e sua justa situação num programa escolar - atletismo e athletica. Educação Physica, Rio de Janeiro, n. 26, p. 10-11 e 71, jan. 1939. 
AZEVEDO, F. Escola anglo-americana: predominancia esportiva. Educação Physica, Rio de Janeiro, n. 14, p. 9-12, jan. 1938.

. Da educação physica, o que ella é, o que tem sido, o que deveria ser. São Paulo, Rio de Janeiro: Weiszflog Irmãos, 1920.

BRASIL. Decreto no 7.247, de 19 de Abril de 1879. Reforma o ensino primario e secundario no municipio da Côrte e o superior em todo o Imperio. Coleção de Leis do Império do Brasil, Rio de Janeiro, p. 196, v. 1, pt. II, 1879. Disponível em: http://www2.camara. gov.br/legin/fed/decret/1824-1899/decreto-7247-19-abril-1879-547933-publicacaooriginal-62862-pe.html. Acesso em: 21 set. 2012.

. Decreto $\mathrm{n}^{\circ} 1.331$, de 17 de fevereiro de 1854 . Aprova o regulamento para a reforma do ensino primário e secundário do município da Corte. Coleção de Leis do Império do Brasil, Rio de Janeiro, p. 45, v. 1, pt. I, 1854. Disponível em: http://www2.camara.gov.br/ legin/fed/decret/1824-1899/decreto-1331-a-17-fevereiro-1854-590146-publicacaooriginal-115292-pe.html. Acesso em: 21 set. 2012.

CAPARROZ, F. Entre a educação física na escola e a educação física da escola. Campinas: Autores Associados, 2007.

CAPRARO, A. M. Identidades Imaginadas: futebol e nação na crônica esportiva brasileira. 2007. 374 f. Tese (Doutorado em História) - Departamento de História. Universidade Federal do Paraná, Curitiba. 2007.

CARVAlHO, J. M. A vida política. In: CARVALHO, J. M. (Coord.). História do Brasil Nação (1808-2010). v. 2. A construção nacional (1830-1889). Rio de Janeiro: Objetiva, 2012. p. 83-130.

CHALHOUB, S. População e sociedade. In: CARVALHO, J. M. (Coord.). História do Brasil Nação (1808-2010). v. 2. A construção nacional (1830-1889). Rio de Janeiro: Objetiva, 2012. p. 37-82.

CUNHA JUNIOR, C. F. Imperial Collegio de Pedro II: o ensino secundário da boa sociedade brasileira. Rio de Janeiro: Apicuri, 2008.

DISCIPLINA e Desporto. Revista de Educação Física do Exército, Rio de Janeiro, n. 8, p. 28, maio. 1933.

DRUMOND, M. Naçôes em jogo. Rio de Janeiro: Apicuri, 2008.

EDITORIAL. Educação Physica, Rio de Janeiro, n. 2, p. 3, 1932.

FERREIRA NETO, A.; MAIA, E. M.; BERMOND, M. T. Revista de Educação Física: ciclo de vida, seção unidade de doutrina e lição de educação física (1932-2002). Movimento, Porto Alegre, v. 9, n. 1, p. 91-118, jan. 2003.

FERRONATO, C. J. Construindo uma nova ordem: o debate educacional na Assembléia Constituinte de 1823. 2006. 165 f. Dissertação (Mestrado em Educação) - Centro de Educação. Universidade Federal da Paraíba, João Pessoa. 2006.

FONSECA, V. M. M. No gozo dos direitos civis: associativismo no Rio de Janeiro, 19031916. Niterói: Muiraquitã, 2008. 
GARCHET, H. M. B. Novos talentos, vícios antigos: os renovadores e a política educacional. Estudos Históricos, Rio de Janeiro, v. 6, n. 11, p. 24-39. 1993.

GÓIS JUNIOR, E.; BATISTA, J. C. F. A introdução da gymnastica na escola normal de São Paulo (1890-1908). Movimento, Porto Alegre, v. 16, n. 3, p. 69-85, jul. 2010.

GOMES, A. C.; DALBEN, A. O controle médico-esportivo no Departamento de Educação Física do Estado de São Paulo: aproximaçóes entre esporte e medicina nas décadas de 1930 e 1940. História, Ciências, Saúde - Manguinhos, v. 18, n. 2, p. 321-336, 2011.

GONDRA, J. G. Artes de civilizar: medicina, higiene e educação escolar na Corte Imperial. Rio de Janeiro: EdUERJ, 2004.

HÉBERT, G. Os perigos morais do Esporte. Educação Física, Rio de Janeiro, n. 65, p. 30-58, 1941.

. Le Sport contre l'Éducation physique. Paris: Librairie Vuibert, 1925.

LINHALES, M. A. A escola, o esporte e a "energizaçáo do caráter": projetos culturais em circulaçáo na Associaçáo Brasileira de Educaçáo (1925-1935). 2006. 267 f. Tese (Doutorado em Educação) - Faculdade de Educação. Universidade Federal de Minas Gerais, Belo Horizonte. 2006.

MACHADO, M. C. G. Rui Barbosa: pensamento e ação. Campinas/Rio de Janeiro: Autores Associados/Casa Rui Barbosa, 2002.

MELO, V. A. O corpo esportivo nas searas tupiniquins - um panorama histórico. In: AMANTINO, M.; PRIORE, M. (Orgs.). História do corpo no Brasil. São Paulo: Editora da Unesp, 2011. p. 123-145.

Das touradas às corridas de cavalo e regatas: primeiros momentos da configuraçáo do campo esportivo no Brasil. In: PRIORE, M.; MELO, V. A. (Orgs.). História do esporte no Brasil: do Império aos dias atuais. São Paulo: Editora Unesp, 2009. p. 35-70.

Cidade Sportiva: primórdios do esporte no Rio de Janeiro. Rio de Janeiro: Relume Dumará/Faperj, 2001.

MENDONÇA, C. S. O sport está deseducando a mocidade brasileira. Rio de Janeiro: Empreza Brasil Editora, 1921.

NETTO, A. R. Ginástica e Desporto. Revista de Educação Física do Exército, Rio de Janeiro, n. 9, p. 29, jun. 1933.

OLIVEIRA, M. A. T.; LINHALES, M. A. Pensar a educação do corpo na e para a escola: indícios no debate educacional brasileiro (1882-1927). Revista Brasileira de Educação, v. 16, n. 47, p. 389-515, mai. 2011.

OLIVEIRA VIANNA, F. J. Instituições Políticas Brasileiras. Belo Horizonte, Itatiaia, Niterói: Ed. UFF, v. 2, 1987.

PAGNI, P. A. Fernando de Azevedo: educador do corpo. 1994. 197 f. Dissertação (Mestrado em Educação) - Programa de Pós-Graduação em Educação. Pontifícia Universidade Católica de São Paulo, São Paulo. 1994. 
PAIVA, F. S. Sobre o pensamento médico-higienista oitocentista e a escolarizaçáo: condiçóes de possibilidade para engendramento do campo da educaçáo física no Brasil. 2003. 451 f. Tese (doutorado) - Faculdade de Educaçâo. Universidade Federal de Minas Gerais, Belo Horizonte. 2003.

PEREIRA, L. A. Footballmania: uma história social no Futebol do Rio de Janeiro, 19021938. Rio de Janeiro: Nova Fronteira, 2000.

RAMOS, S. Indivíduo, Esporte e Raça. Revista de Educação Física do Exército, Rio de Janeiro, n. 31, p. 38, mai. 1936.

REGGI, J. P. Para que o esporte não cause dano. Educação Física, Rio de Janeiro, n. 60, p. 16-17 e 36, nov. 1941.

RESENDE, O. M. Os sports colletivos como arma de combate aos instinctos egoisticos. Educação Physica, Rio de Janeiro, n. 5, p.15, 1932a.

. Os sports como elemento de cohesão nacional. Educação Physica, Rio de Janeiro, n. 2, p. 51, 1932 b.

SCHNEIDER, O. Educação Physica: a arqueologia de um impresso. Vitória: Edufes, 2010.

SCHNEIDER, O.; FERREIRA NETO, A. Americanismo e a Fabricação do "Homem Novo": Circulação e Apropriação de Modelos Culturais na Revista Educação Physica (1932-1945). Movimento, Porto Alegre, v. 14, n. 1, p. 135-159, jan. 2008.

SILVA, C. L. B.; MELO, V. A. Fabricando o soldado, forjando o cidadão: o doutor Eduardo Augusto Pereira de Abreu, a Guerra do Paraguai e a educação física no Brasil. História, Ciências, Saúde - Manguinhos, Rio de Janeiro, v. 18, n. 2, p. 337-353, jun. 2011.

SOARES, A. J. G.; LOVISOLO, H. R. Futebol é fogo de palha: a profecia de Graciliano Ramos. Revista do Núcleo de Sociologia do Futebol da Uerj, Rio de Janeiro, v. 5, p. 7-20, 1997.

STEINBERG, R. Nem todos são iguaes em face dos esportes. Educação Physica, Rio de Janeiro, n. 13, p. 35, dez. 1937.

TESCHE, L. O Turnen, a Educação e a Educação Física nas escolas teuto-brasileiras, no Rio Grande do Sul: 1852-1940. Ijuí-RS: Editora Unijuí, 2002.

VECHIA, A.; LORENZ, K. M. Fernando de Azevedo e a questão da "raça brasileira": sua regeneração pela educação física. Cadernos de História da Educação, v. 8, n. 1, p. 57-70, jan. 2009.

VINTRE, C. O perigo dos esportes de competição nas escolas primárias. Educação Física, Rio de Janeiro, n. 51, p. 10-11 e 69, fev. 1941.

WEBER, E. França: fin de siècle. São Paulo: Companhia das Letras, 1988.

Recebido em 03 de julho de 2013.

Aprovado em 26 de maio de 2015.

DOI: $\underline{\text { http://dx.doi.org/10.1590/ES0101-73302015120113 }}$ 